\title{
TURBULENT BUSINESS ENVIRONMENT AND THE POSSIBILITY OF APPLYING MARKETING DECISION OPTIMIZATION ALGORITHMS USING THE EXAMPLE OF THE LATVIAN MARKET
}

\author{
Ludmila Bahmane \\ "RISEBA", University of Business, Arts and Technology, Latvia
}

\begin{abstract}
In this work an attempt is made to describe the experience of marketing decision development in the conditions of a turbulent business environment using the example of various Latvian enterprises. The main goal is to show the possibility of simple algorithm for strategic marketing solutions development of different business structures in Latvian market, which can be easily mastered by students of the 2-nd or 3-rd years during 100 academic hours. Using characteristic features of a turbulent business environment, the possibilities of applying marketing decisions offering algorithms both for the national (Latvian) market and for entry into international markets are discussed. This experience is part of the author's pedagogical activity at higher education institutions in Latvia (RISEBA) over the last 20 years and assumes training in new methods of marketing decision development, with use of modern marketing technologies, including matrix methods, as well as cluster, discriminant and screening analysis. The researched experience and potential for the application of the author's theoretical elaborations (the matrix "solution's novelty - consumer's demand for novelty") are particularly relevant for developing creative marketing management solutions in the areas of business where the novelty of goods (services) may be an important competitive advantage in a turbulent business environment.
\end{abstract}

Keywords: algorithms for marketing decision development, adapted to market conditions; consumers' demand for creativity; marketing management; turbulent business environment.

\section{Introduction}

The concept of "organization" involves different approaches for a researcher: An organization is a group of people who coordinate their activities to achieve common purposes (Meskon et al., 1998). Organization is also a process of enterprise structure creation, which allows efficient cooperation of people to achieve goals of the enterprise (Thompson \& Strickland, 1995). Organization is systematic coordination and taking actions to complete specific tasks (Atkinson \& Wilson, 1996). An organization is a separate association of people who interact in achieving certain purposes and completing certain tasks (Maslow, 1966), (Porter, 2008). Based on the definition of P. Doyle (2002), situational management is management in conditions oriented towards the occurrence of 
Bahmane, 2018. Turbulent Business Environment and the Possibility of Applying Marketing Decision Optimization Algorithms Using the Example of the Latvian Market

unforeseen circumstances. In this case tactics are the best option for implementation of strategy in specific conditions which consider and utilize unforeseen circumstances. One of the most important organizational features of such an approach is its connection with the external environment. No organization can be isolated as an "island on its own". Organizations totally depend on the world around them - the external environment - both in relation to their resources and relative to customers, the users of their results to be achieved. Organizations exist in a surrounding environment consisting of many elements: a market with its offers and demands; shareholders with their interests in gaining dividends and implementing ownership rights; partners whom the organization is obligated to; requirements for product quality; education of assigned people; increasing demands of salaried workers; activities of competitors, consequences of economic crises, etc. (Kotler \& Keller, 2012), (McDonald, 2002).

The environment influences an organization and has its requirements. The head director must consider this significant influence. These interconnected factors influence everything that happens in the organization and they change continually. The organization totally depends on the external environment; this environment, however, is out of the manager's control. How should such a situation be handled? Via situation simulation? Even though simulation experience and possibilities in the practical field are growing (Ostervalder, 2010), the real application of these methods in the practice of small and medium-size business management is limited due to methodological and economic reasons.

The main goal is to show the possibility of simple algorithm for strategic marketing solutions development of different business structures in Latvian market, which can be easily mastered by students of the 2-nd or 3-rd years during 100 academic hours.

\section{Aims of the research:}

1) Discuss how the algorithm proposed in this article can be used for search of marketing solutions for other business environments and conditions.

2) Discuss whether knowledge of manager is sufficient to use proposed algorithm.

The topics of this research:

1) What would be an algorithm for training creatively thinking marketing students, if it is assumed that an algorithm is a logical sequence of steps for solution of a specific task?

2) What methods and technologies will teach marketing students training at higher education institutions to find and solve problems in a real market environment?

3) How can we instil interest in finding non-standard marketing solutions? 
The author asked herself these questions in her pedagogical work at Latvian higher education institutions - RAU (from 1992), TSI (from 1994), and RISEBA (from 1997) - during the process of training control specialists.

The author agrees with N. Avdeyev, that the problem can be solved through directed teaching of modern analysis methods, quickly searching within possible marketing solutions, choosing the effective one or developing and offering one's own solution, if there are no effective solutions. To achieve this, the student must be able to undertake:

1) type of solution - solutions that have a specific algorithm already known to the student.

2) type of solution - from a variety of viable solutions, the student should choose the most correct one. The student knows the existing criteria for choosing effective solutions.

3) type of solution - solving non-typical tasks. The student should analyse unfamiliar situations and information and generate latest information.

4) type of solution - the ability to see new connections and possibilities with further generation of entirely latest information in the conditions of a turbulent external environment. The elements of creativity are objectively essential for this type of problem (Bahmane, 2015).

\section{The organization and transformation of the external environment}

The conditions of business structures are complicated due to new requirements. With every year company leadership must consider not only an increasingly greater number of external environment factors, but also the fact that they are becoming global in nature. To succeed, companies have to compete in foreign markets and withstand competition from foreign companies in their homeland. For Latvian businesspeople, an important and objective factor is the national market volume and the development level. Based on the latest data, there are 1.97 million inhabitants at most in Latvia (2016). The new conditions require an understanding of entirely new fields of jurisprudence and marketing and recognition of new cultural values (Solomon, 2014), (Hammer \& Champy, 2009). For small and medium-size businesses in small countries, this is especially difficult to achieve in management. Let us consider a few aspects of external business environment factors used in the marketing management of organizations (Kotler \& Keller, 2012).

The external environment cannot remain constant; it is always changing. Thus, it is possible to distinguish an environment with slow changes of parameters and another environment with fast and unpredictable changes. In modern marketing, the factor of environmental changes considered in the management of a specific organization has been researched by multiple authors. For example, 
Bahmane, 2018. Turbulent Business Environment and the Possibility of Applying Marketing Decision Optimization Algorithms Using the Example of the Latvian Market

Boddy P. and Paton R. (1998), and Michael Hammer and James Champy, in their book "Reengineering Corporation" (1998), claim that up until 1975, the external environment of organizations was stable, with rare global cataclysms and insignificant changes, i.e. at that time it was possible to talk about the existence of a "calm" external environment. Managers of that time needed to organize their enterprises so that they could utilize all the opportunities provided by such an environment around them. A “calm" external environment is characterized by: use of long product lifetime cycles (technologies, services); increase in the size of companies with a pyramidal structure - containing their own expert divisions; domination of mass production; large storage spaces for raw materials and finished products (Ostervalder, 2010), (Moore, 2011).

\section{The turbulent business environment as a new factor of marketing management}

The same authors claim that starting from the end of the 1970s and the beginning of the 1980s, the situation became more complicated. One of the many causes was rapid scientific and technical progress, i.e. the factor of the business environment and its parameter changes led to specialists discussing organization management in the conditions of a "variable external environment". The variable external environment is characterized by increased instability and unpredictability, and the behaviour of managers is significantly more complicated than their actions in a "calm" environment. Over time, quantity was replaced by new quality, i.e. there were global changes that led to a new concept of the "global environment". Because of the uniform transition of the external environment from a "calm" condition to variable, global changes occurred in the main economic ratings of the environment. The following can be mentioned: a sharp reduction of products' lifetime cycles; a reduction of products' development time frames; unprofitable storage spaces; changes in the requirements of the technical organization subsystem; more complex products; changes in relations between the customer and the manufacturer (confidence in competency); maintenance of a company's own unrealistic specialized science-intensive services; the customer dictates suppliers; toughened competition; prices are no longer the main requirement in cooperation. Management attempted to find new methods and forms of business management (Zagula \& Tong, 2004).

Then marketing management came to scene, so in addition to P. Kotler some new marketing gurus appeared - Z. Z. Lambin (Lambin, 1994), the Swedish marketing school (Best, 2005). However, new management possibilities do not always make it to small and medium-size businesses in time, and new forms of old marketing economy problems have appeared. The crisis has become global and crisis management has appeared (Ansoff, 2007). Specialists have started to 
say that during the last 10 years the business environment has changed completely (Zagula \& Tong, 2004), (Moore, 2011). The concept of turbulence was borrowed from physics and soon enough it was incorporated into the concept of a "turbulent business environment". (Bahmane, 2010). Not only changes in environmental factors have been forecasted, but also changes in rules based on which organizations are to operate. And these rules are changing quickly and unpredictably. The latest example - the withdrawal of Great Britain from the EU. What will happen to Latvian companies? How should small and medium-size business management of these organizations be performed?

It is thought that in such turbulent environments the highest priority is the ability of organizations to adapt quickly and survive, (Moore, 2011). A turbulent environment has these requirements, and enterprises existing in such conditions must obey. Conditions "sound" more like requirements since managers of a company, no matter how strong it is, will not "catch" changes in the environment and make changes to a company in time, so after a short period of time it will already be too late to do anything, and former positions will be lost to more advanced competitors. In short, these are the requirements: decreasing organization size; reengineering; constant tracking of the situation in the external environment; deployment of a "just-in-time" production system. It is well known that for "just-in-time" production, the parts are manufactured at precisely specified moments, so defects are found and their causes are eliminated immediately while the product moves from one position to another, ideally without storage.

Adaptability is the most important condition for an organization's survival in an unstable/turbulent external environment| (Moore, 2011). The common external environment (macro environment) and accounting for its requirements in marketing management is becoming the most important condition for survival of small and medium-size businesses, especially in small countries. Analysis of strategic marketing decision development and adoption experience allows the author to claim that use of well-known (but not widely used) techniques for management solution development will allow one to find adequate solutions for a turbulent environment, including a strategic solution (Bahmane, 2010).

\section{An algorithm as a method of marketing decision-making in a turbulent business environment}

The optimality criteria for marketing solution development are as follows: 1) decreasing risks 2) going through all possible solution variants. It is necessary to formulate an algorithm as a logical sequence of actions to solve a specific task. The Toyota Way, Principle 6 (Liker, 2003), states that standard tasks are the basis for continuous improvement and delegation of authority to employees. 
Bahmane, 2018. Turbulent Business Environment and the Possibility of Applying Marketing Decision Optimization Algorithms Using the Example of the Latvian Market

During the training of specialists at higher education institutions, from the author's point of view, solutions are required for the task of new complexity: Determine a possible algorithm for creatively thinking specialists training in the marketing field, who can find a new, i.e. creative, solution for market demands with understanding of time being a real necessity in such a solution.

The 1st algorithm - to improve competitive positions in the Latvian market

The experience of the author in training marketing solution development specialists (Bahmane, 2015) made it possible to formulate the 1st algorithm. Its purpose is to improve an organization's competitive positions in the Latvian market.

\begin{tabular}{|c|c|c|c|}
\hline \multicolumn{4}{|l|}{$\begin{array}{l}\text { Level of } \\
\text { solution's } \\
\text { creativity }\end{array}$} \\
\hline Maximum & $\begin{array}{l}2 \\
\text { Strategy of quality } \\
\text { increase (company } \\
\text { image strategy, } \\
\text { strategy of leadership } \\
\text { in the field) }\end{array}$ & $\begin{array}{l}4 \\
\text { Benchmarking } \\
\text { strategy (strategy of } \\
\text { new products, } \\
\text { superquality, strategy } \\
\text { of world leadership) }\end{array}$ & \\
\hline \multirow[t]{2}{*}{ Minimum } & $\begin{array}{l}1 \\
\text { Strategy of proven } \\
\text { quality (product brand } \\
\text { strategy) }\end{array}$ & $\begin{array}{l}3 \\
\text { Strategy of new } \\
\text { products (strategy of } \\
\text { innovator image, } \\
\text { strategy of niche } \\
\text { leader) }\end{array}$ & \\
\hline & Minimum & Maximum & $\begin{array}{l}\text { Consumer's } \\
\text { demand for } \\
\text { novelty }\end{array}$ \\
\hline
\end{tabular}

Figure 1. “Solution's novelty - consumer's demand for novelty” matrix (source: created by author)

For this, RISEBA students of the 2nd and even the 1st years can successfully perform the following:

1) Choose a real company which operates in the Latvian (European) market.

2) Define symptoms of a problem, the basis of the problem, a research design. Construct a graph of problems and solutions.

3) Evaluate the influence of macro environment factors on company activities via PEST methods. Characterize the business environment. Is it stable? Variable? Turbulent? What is the company mission in these conditions? 
4) Create a concept of the base market. Perform macro segmentation of the market through one of the standard methods (Abel method, "fish", "net", three-dimensional matrix).

5) Analyse the competition, (according to Porter) one of the most dangerous factors for a company. Construct a SWOT (Strength, Weaknesses, Opportunities and Threats) matrix.

6) Perform micro segmentation of the market, identify and justify the market segment which will be the most attractive for the company. Use the VALS2 ("Values and Lifestyles 2") and GLOBAL SKAN methods. (Kotler \& Keller, 2012), (Solomon, 2014). Provide the products' overall positioning and positioning options for the selected segment by using correlation or cluster analysis.

7) Analyse product distribution channels - how well do they match the requirements of the target market segment - by using the semantic differential method.

8) Research pricing strategy and company tactics regarding the selected market segment with maximum use of the "price-quality matrix", a common competition matrix (Porter, 2008).

9) Develop an improved communications strategy oriented towards the selected market segment.

10) Based on the McKinsey matrix (Doyle, 2002), determine the main competition strategies for the Latvian market.

11) Based on a "solution's novelty - consumer's demand for novelty" matrix (Bahmane, 2005), determine marketing strategies for the analysed company.

Matrix methods are used for finding effective and rather standard marketing solutions from the first lecture at a higher education institution. These methods provide possible variants of marketing solutions; however, application of these results is often limited since real life in business structures is more complicated than in theory. Students can see the limitations of their solutions and the necessity of creativity and trying to find something new. For most of them, this removes the fear of offering novel solutions, while support and loyal criticism of the lecturer allows them to see their mistakes and lack of information and teaches them to analyse and go beyond what they know. It is important to note that in addition to widely used and well-known matrices (Porter's, Ansoff's, Boston's, McKinsey, SWOT), (Kotler, 1997), (Boddy \& Paton, 1998), (Doyl, 2002), the author's matrix "solution's novelty - consumer's demand for novelty" is also discussed. (Bahmane, 2005), (Figure 1). 
Bahmane, 2018. Turbulent Business Environment and the Possibility of Applying Marketing Decision Optimization Algorithms Using the Example of the Latvian Market

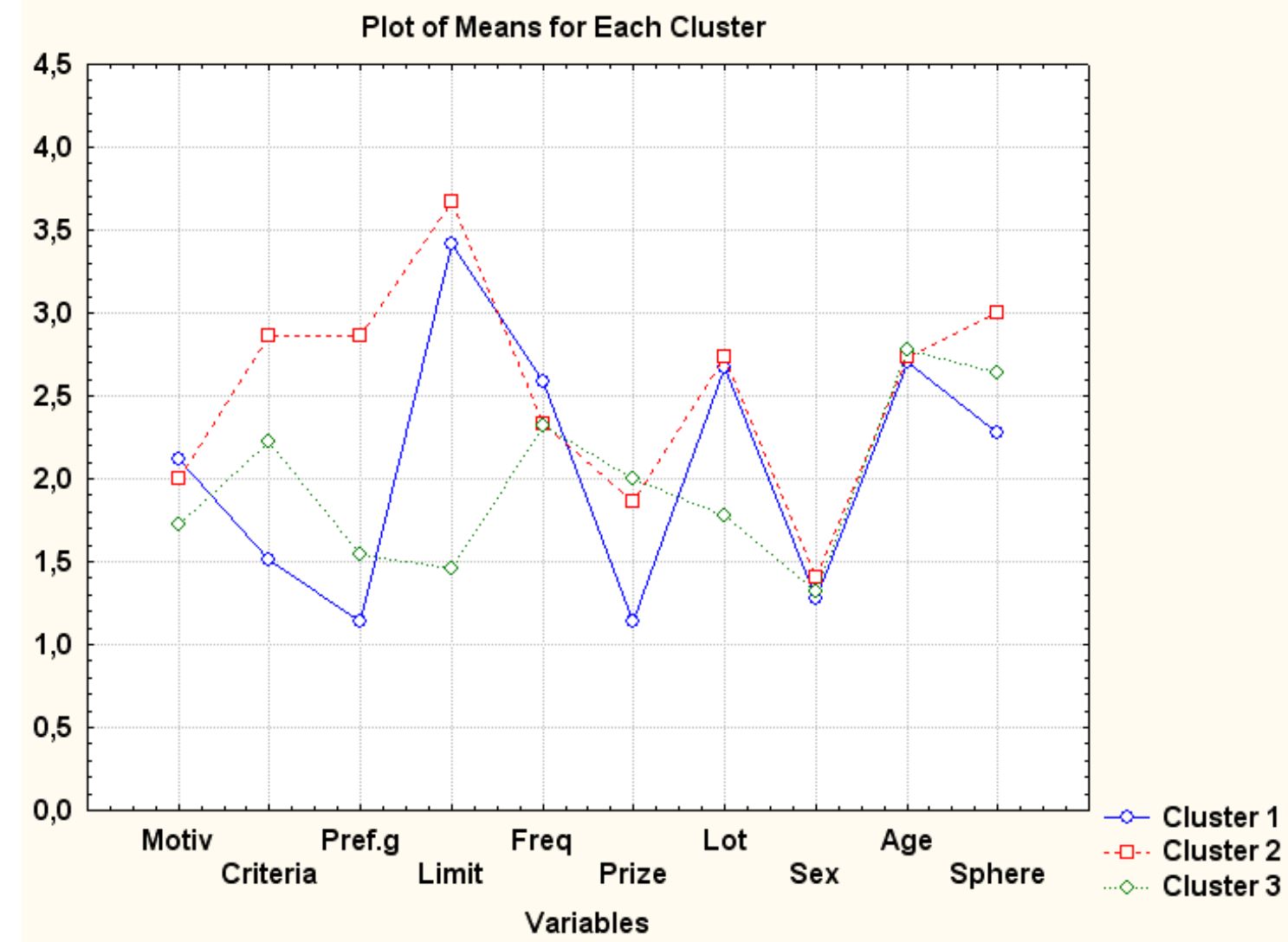

Figure 2. Customer clusters of gambling services (Riga) (source: created by author)

Students are taught to analyse conducted research by means of cluster analysis (Figure 2) in different situations and for different objects. Thus, use of cluster analysis (Bahmane, 2015), (Figure 2) allows them to describe gambling services' customer profiles from objective and subjective points of view, identifying the specifics of Riga and Daugavpils gamblers, determining target groups (segments) of bingo-club visitors, and identifying the specifics of customer behaviour, including an evaluation of “solution's novelty - consumer's demand for novelty" for strategic decisions on extending the list of offered games and required investments in a specific market and time situation. The main criteria in the choice of gambling room for Dimanta Bingo customers in Riga and Daugavpils are quality of service and a convenient location. The main motivation of customers visiting a gambling room is the desire for relaxation and then gambling excitement. By using cluster analysis, gamblers of Dimanta Bingo in Riga have been divided into "true bingo lovers" (53 \%), "privileged innovators" (18.5 \%) and “excited” (27.5 \%). Gamblers of Dimanta Bingo in Daugavpils were divided into "partiers" (31 \%), "rational enthusiasts" (32 \%) and "excited optimists” (over 36 \%). 
It can be concluded from the "solution's novelty - consumer's demand for novelty" matrix that presently the organization is situated in the 1st quadrant and uses the "strategy of proven service quality". Since the company is growing and has strong positions in the gambling market, its further development should be based on the 2nd strategy - the "strategy of increasing gambling services' quality", "image forming”. This means that no new investments are required.

The use of cluster analysis allows the student not only to find new solutions, but also to search for more efficient non-existing marketing solutions, i.e. creative ones. Cluster analysis and segmentation offers companies the possibility to understand their clients and customers more deeply and evaluate their priorities and necessities when making a real choice.

\section{The 2nd algorithm - to conquer a strong position in a foreign market}

The 2nd algorithm - the main goal of the company is to conquer a strong position in a foreign market by researching all marketing possibilities in the quickest fashion. This method has been used at RISEBA for 5 years in a test about international marketing by students of the 3rd year for various business structures - from gambling businesses to banks. More complex variants, such as searching with optimal criteria, relative analysis of chosen countries and detailed research of competition, become part of bachelor's or master's theses.

Stages of the 2nd algorithm's implementation:

1st stage. The screening analysis method allows one to solve almost any unsolvable task: how to perform a maximally complete analysis of market possibilities with limited company possibilities (personnel, time, resources).

2nd stage. The screening analysis method offers additional possibilities for precision, additional correction of the strategy, i.e. change of criteria, adapting criteria to specific conditions.

3rd stage. The method of environment sectioning allows one to determine the specifics of the macro environment and the market in potentially attractive countries.

4th stage. Use of a marketing mix model - the 7Ps - allows the company to match the needs of target consumers in each selected country with the marketing possibilities of the company.

Survival of small and medium-size businesses in the turbulent variable conditions of the Latvian market entirely depends on their focused research of new export opportunities. An example of a small Latvian company, SIA ProBaltic, shows that in conditions of market internationalization, accessible internet technologies, and use of screening analysis databases and matrix methods, it is possible to search for an optimal marketing strategy for entering foreign markets via cabinet research (Bahmane, 2010). 
Bahmane, 2018. Turbulent Business Environment and the Possibility of Applying Marketing Decision Optimization Algorithms Using the Example of the Latvian Market

Screening analysis, in turn, has a series of sequential stages - a specific algorithm for an optimal solution search in selected countries and markets where a company's products (services) can find a competitive niche. According to V. Cherenkov (Черенков, 2006), the required stages can be described as follows:

1) The basis for analysis is determined: characteristics of company activities that make products (services) unique and improve their competitiveness.

2) The conditions for searching for new markets is determined - the strategy of the company is formed - standardization or adaptation of further searches: either searching for markets which are ready to accept the company's products or searching for products that are in demand in markets known to the company. This solution is determined by competitive (unique) company products' (services') features.

Screening analysis allows one to create a list of top priority countries by a focused search of over 236 countries using MS Excel software, including conditional formatting tools.

\section{1st filter. Macro environment.}

Takes into account: social-cultural norms, political-legal norms, the economic condition of the country, a geographical location.

Suggested search criteria: customs tax, the average income level per capita, a great distance between importer and exporter countries, a small population of the importer country, political disagreements between both countries (economic sanctions, ban on imports).

Preliminary possibilities: Austria, Belgium, Croatia, the Czech Republic, Denmark, Estonia, Finland, France, Germany Greece, Hungary, Ireland, Italy, Lithuania, the Netherlands, Norway, Poland, Portugal, Russia, Saudi Arabia, the Slovak Republic, Spain, Sweden, Switzerland, Turkey, the United Arab Emirates, the United Kingdom, Israel.

\section{2nd filter. Specific product acceptance specifics in each region.}

Takes into account: religious factors, informational support, historical premises, ethical norms and traditions, market development stages.

Suggested search criteria: Muslim countries excluded, no information about the market in a specific country, relatively few imports, presence of consumers related to the exporting country in any way.

More precise possibilities: Belgium, Estonia, France, Germany, Ireland, Italy, Lithuania, the Netherlands, Russia, Spain, the United Kingdom.

\section{3rd filter. Specific factors influencing exports.}

Takes into account: competition in the local market, similar substitutes for a specific product, forecasted and real data for sales of similar products in a given market, the rate of products' acceptance by consumers, market entry expenses. 
Suggested search criteria: too much competition in the local market, substantial number of similar, mutually exclusive products, the worst forecast for the market, high expenses for entering a specific market.

The most probable possibilities: Germany, France, Italy, the Netherlands, Spain.

\section{4th filter. Target markets.}

As a result, a list of top priority countries is prepared to search in a specific niche. Presence of consumers with an ethnicity like Latvian people

The most probable possibilities: Germany, the Netherlands.

As a result, an estimation of macro environment factors is made in the conditions of a turbulent business environment. This allows business structures to define a competition position at a given moment, to find "anchors", which will allow them to develop and improve strategies.

An example of a potential export market screening analysis method is shown below for the products of JSC Latvijas maiznieks. A conditional scheme of the screening analysis was made: JSC Latvijas maiznieks already exports its products to Latvia's closest neighbours, i.e. Lithuania and Estonia. Also, exports of confectionary products to Great Britain and Ireland were established in 2014, i.e. to the countries where many ethnic Latvians, Lithuanians, Estonians, and Poles live, who have tried products from Latvijas maiznieks multiple times before. These countries will not be considered as potential partners in the screening analysis.

What should be considered during a screening analysis? When choosing countries that are most appropriate for exporting Latvijas maiznieks products, the researcher chooses country features that have the greatest influence (or can possibly have such influence). Thus, a screening analysis was started with the exclusion of 4 countries already among the importers of AS Latvijas maiznieks, which are: Estonia, Lithuania, Great Britain and Ireland. It was possible to skip this step and check whether the intuitively made choice matches the logical search of variants per selected criteria.

So, there were 236 countries of the world initially. The main (first) criteria used to select variants was gross national income per capita in the country per year. This can be calculated by dividing national income by the population of the country. Income per capita as a rating is totally different from gross domestic product and gross national product per capita. For international comparisons, income per capita is recalculated into a single currency, usually the US dollar. Since no purchasing power differences in various countries are considered this way, purchasing power parity recalculation is preferred.

Countries can be divided into:

- $\quad$ countries with a high level of income per capita (over \$12,616); 
Bahmane, 2018. Turbulent Business Environment and the Possibility of Applying Marketing Decision Optimization Algorithms Using the Example of the Latvian Market

- $\quad$ countries with a medium level of income per capita (from $\$ 1,036$ to $\$ 12,615)$;

- $\quad$ countries with a low level of income per capita (below \$1,035).

This way, the first filter is passed only by countries with an elevated level of income per capita, i.e. over $\$ 12,000$.

Political-legal form. The screening analysis filter is passed by countries of the EU, i.e. exports to these countries are not subject to customs dues. Also, the greatest importing country of Latvia is excluded - Russia. Due to the latest political and economic events in the world, this country imposed an embargo on significant groups of food products imported to their country. These groups include products of AS Latvijas maiznieks.

\section{Population}

The screening analysis filter prevents countries with a population below 2 million people from passing.

\section{Ethical norms and traditions}

The filter excludes countries where it is historically uncommon to use flour products in the way AS Latvijas maiznieks provides.

\section{Geographical location}

Since AS Latvijas maiznieks doesn't use E additives during production, the product can't be stored for a long time. Thus, delivery to the importing country should be performed in the shortest terms without spending a lot of time on transportation. This way, the screening analysis filter excludes countries with a distance of over 1,000 km from Latvia. Great distances between countries increase the costs of shipping products as well, which makes the price less competitive in the target market.

\section{Taxes and dues (VAT payers)}

The filter excludes countries that are not members of the EU Economic Area and have customs taxes on imports. (Choice of criteria could be different.)

\section{Ease of entering the market}

The markets of Germany, the Netherlands, Spain and Italy have considerable competition between both local and foreign manufacturers. Entering the market is also difficult because of the conservative views of the local population on food products. It is proposed that the focus of the company should be made on visitors from these countries, who are more open to changes in their usual routine and who are mostly familiar with the quality and taste of these confectionary products. So, Italy and Spain do not pass this filter. 


\section{Conclusions}

Based on the results of the screening analysis, 2 countries are selected for exports - the countries that most precisely match the needs of the environment at the present stage of the organization Latvijas maiznieks. These countries are Germany and the Netherlands. For these countries, environment segmentation and a strategy for entry are developed and a marketing mix 7Ps package is justified. Results of the research

1) Use of controlled creativity of solutions is a real option in finding ways to achieve the goals of any business structure in the conditions of a turbulent external environment.

2) Use of algorithms for developing standard marketing solutions allows for fast and adequate research of specific business environment features and offers an adaptive marketing solution adequate for an organization.

3) If the situation is unclear, the use of complex approaches (matrices, clusters, discriminant analysis, the Jefremov-Zade method (a variation of PEST) allows for a nonstandard approach to solving problems (Bahmane, 2007) regarding national market conditions. This makes it possible to enter the 3rd and 4th levels of creative thinking development in training marketing specialists.

4) Use of the matrix "solution's novelty - consumer's demand for novelty" (Bahmane, 2005) in the process of marketing solution development allows specialists to find new aspects of adaptive marketing solution development.

5) In conditions of turbulence - unpredictably and quickly varying factors in the business environment - adaptation comes in the form of marketing strategy, especially for small and medium-size businesses of Latvia.

\section{Additional conclusions:}

1) The model of student training (including marketing managers) in development and use of creative solutions shows its practicality in the example of various business types, times and even different skills of students.

2) Knowledge of modern inter-marketing techniques and working experience removes young specialists' fears of making expected management decisions, including creative ones.

3) Young specialists, even as students, understand and comprehend the possibilities of using modern methods and algorithms to find adaptive marketing solutions in the conditions of turbulent business environments. 
Bahmane, 2018. Turbulent Business Environment and the Possibility of Applying Marketing Decision Optimization Algorithms Using the Example of the Latvian Market

\section{Conclusions on algorithm mastering and applications:}

1) The proposed algorithm can be successfully mastered during 100 academic hours and 3 study courses by students-managers.

2) The proposed algorithm can be easily adopted to new requirements in conditions of turbulent business environment, considering new methods and technologies of marketing management.

3) Students (managers) can determine the complexity of algorithm application required by Latvian market specifics.

\section{References}

Ansoff, H. I. (2007). Strategic Management Classic Edition. Palgrave Macmillan.

Atkinson, J., \& Wilson, J. (1996). Strategic Marketing: Cases, Concepts and Challenges. HarperCollins Publishers.

Bahmane, L. (2005). Cluster Analysis as the Method of Subject Segmentation of European Development Funds of Small and Medium-Sized Business in Latvia. Proceedings of the 5th International Conference "Reliability and Statistics in Transportation and Communication".

Bahmane, L. (2010). Development of Strategic Marketing Solutions in Circumstances of Rapidly Changing External Environment. Proceedings of the 10th International Conference "Reliability and Statistics in Transportation and Communication", 255-260.

Bahmane, L. (2015). Creativity as a Condition for Achieving an Affective Higher Education Marketing Specialists Upbringing (Experience and Problems). Society. Integration. Education. Proceedings of the International Scientific Conference. Volume 1.

Best, R. J. (2005). Market-Based Management. Strategies for Growing, Customer Value and Profitability. 4th edition. Prentice Hall.

Boddy, D., \& Paton, R. (1998). Management. An introduction. Prentice-Hall Europe.

Doyle, P. (2002). Marketing management and strategy. Prentice Hall.

Hammer, M., \& Champy, D. (2009). Reengineering the Corporation: A Manifesto for Business Revolution. HarperBusiness Essentials.

Kotler, P. (1997). Marketing Management: Analysis, Planning, Implementation and Control. Prentice-Hall International.

Kotler, P., \& Keller, L. K. (2012). Marketing Management, 14th Edition. Pearson.

Lambin, J.- J. (1994). Le Marketing Strategique. Une perspective europeenne. [Strategic Marketing. A European Perspective] 3-rd edition. Ediscience International.

Liker, G. R. (2003). The Toyota Way: 14 Management Principles from the World's Greatest Manufacturer, New York, NY: HarperBusiness.

Maslow, A. (1966). The psychology of science, N.Y.

McDonald, M. (2002). Marketing Plans. How to Prepare Them. How to Use Them. N.Y.

Meskon, M. Albert, M., \& Khedouri, F. (1988). Management. N.Y.

Moore, G. A. (2011). Escape Velocity. Free Your Company's Future From The Pull Of The Past, New York, NY: HarperBusiness.

Osterwalder, A. (2010). Business Model Generation. Hoboken: John Wiley et Sons.Inc.

Solomon, M. R. (2014). Consumer Behavior: Buying, Having, and Being (11th Edition), Pearson. 
SOCIETY. INTEGRATION. EDUCATION Proceedings of the International Scientific Conference. Volume VI, May $25^{\text {th }}-26^{\text {th }}$, 2018. 53-67

Porter, M. E. (2008). On Competition: Updated and Expanded Edition. Boston: Harvard Business School Publishing.

Tompson, A., \& Strickland, A. (1995). Crafting \& Implementing Strategy. Text and Readings. 6 th Edition, IRWIN.

Zagula, J., \& Tong, R. (2004). The Marketing Playbook. Five Battle-Tested Plays for Capturing and Keeping the Lead in Any Market. Portfolio.

Черенков, В. И. (2006). Международный бизнес. Учебно-методический комплекс. [International Business. Training and metodology complex]. Rostov na Donu: Feniks. 